Gut, 1983, 24, 914-920

\title{
Histological changes following Nd YAG laser photocoagulation of canine gastric mucosa
}

\author{
D F KELLY, S G BOWN, B M CALDER, H PEARSON, B M Q WEAVER, \\ C P SWAIN, AND P R SALMON
}

From the Departments of Pathology, Medicine and Veterinary Surgery, University of Bristol, Bristol; and the Rayne Institute, University College Hospital, London

SUMmaRY Tissue changes produced in the dog stomach by exposure to a Nd YAG laser varied from mild mucosal oedema to cell vaporisation. Intermediate degrees of damage caused a marked inflammatory response leading to extensive fibrosis in the submucosa and muscularis propria. The true extent of tissue damage was not apparent immediately, and treated mucosa that initially appeared intact sometimes sloughed several days later to leave an ulcer. The extent of damage and the rate of healing depended on the amount of laser energy used. With pulses at optimum laser power $(75 \mathrm{w})$ and exposure time $(0.4 \mathrm{sec})$, however, haemostasis was achieved in induced ulcers with total energy concentrations that did not produce full thickness tissue damage nor alter the healing rate from that observed in untreated ulcers. Thermal contraction was the primary haemostatic mechanism, thrombosis only occurring as a secondary effect.

Endoscopic Nd YAG laser photocoagulation has been shown to be effective for the treatment of bleeding peptic ulcers in pilot clinical studies, ${ }^{1}$ although reservations have been expressed about its safety. ${ }^{2}$ Recent experimental work has established which factors determine the safety and efficacy of this treatment and that good haemostasis can be achieved with acceptable degrees of tissue damage $^{34}$ This paper documents the histological features of the changes produced experimentally in the stomach wall from a few minutes to 35 days after exposure to the laser. These changes are discussed in relation to the laser power and exposure time and the arrest of haemorrhage from induced ulcers.

\section{Methods}

We used the MBB Medilas Nd YAG laser system in these experiments. This is a continuous wave laser with a maximum output of $90 \mathrm{w}$ and can be adjusted to give pulses of a fixed duration from $0 \cdot 1-5$ seconds. The arrangement of the fibre transmission system for the laser beam, the experimental procedures and the morphological methods used have been described previously. ${ }^{35}$ Initial studies on the effect of the laser on normal tissue were

Address for correspondence: Dr S G Bown. Faculty of Clinical Sciences. University College, The Rayne Institute, 5 University Street, London, WC1E 6JJ.

Received for publication 29 December 1982 performed by creating lesions on intact mucosa varying the laser power (from 25-75 w), the time of exposure (from 1-5 seconds) and the distance between the fibre tip and the tissue (from 5-20 mm). Haemostasis studies were carried out in heparinised animals on ulcers made in the stomach with a Quinton ulcer maker. ${ }^{6}$ These bleeding ulcers were treated with repeated pulses of various durations (from 0.1-1 second) and powers (from 25-90 w). All lesions produced on intact mucosa, laser treated ulcers and untreated control ulcers were identified by suture markers for later histological examination.

OBSERVATIONS ON TREATED MUCOSA

The descriptive terms used in this section are those in our earlier report. ${ }^{5}$

\section{Normal mucosa: 30 minutes after laser treatment (acute lesions)}

The extent of change depended on the total energy applied, and varied from mild mucosal effects to changes extending through the full thickness of the external muscle layer. At 30 Joules, only detachment of the surface epithelium and in situ mucosal damage was seen. At higher energies, damage to the muscularis mucosae was followed by connective tissue 'burns' in the submucosa (Fig. 1), and over $100 \mathrm{~J}$, damage was seen in the external muscle layer in some sections. In the damaged submucosa, vessels were patent and had intact walls. There was no evidence of thrombosis but there was 


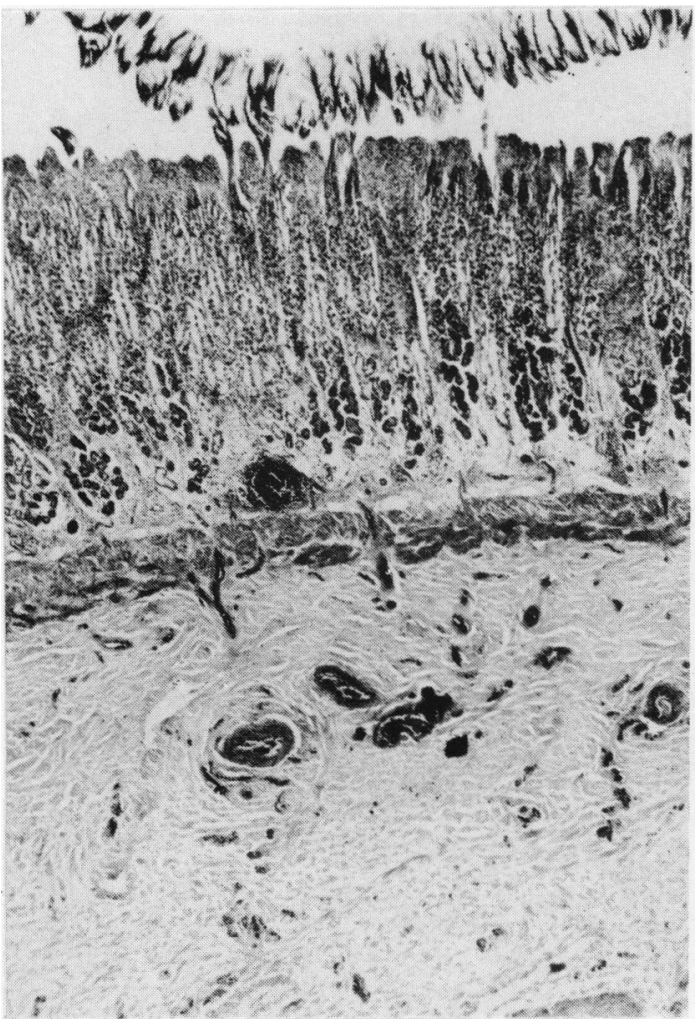

Fig. 1 Acute laser injury $(70 w, 5 \mathrm{sec})$. Detachment of surface epithelium, in situ mucosal damage and submucosal connective tissue burn. Haematoxylin and eosin $(H \& E$ $\times 36$ original magnification).

hyperaemia and oedema in the mucosa and submucosa. At high energies ( $75 \mathrm{w}$ for $3 \mathrm{sec}=225 \mathrm{~J}$ ) with the laser fibre close to the mucosa $(5 \mathrm{~mm})$, mucosal cells 'exploded', leaving a small hole, whose depth could be further increased by applying the laser for even longer periods at the high power level. At lower energies cells were not vaporised, however, and the mucosa remained macroscopically intact even when changes were detectable histologically through the full thickness of the external muscle layer.

\section{Four days after laser treatment}

The extent of change depended on the energy applied, but the damage seen at this stage was considerably greater than that seen in the acute lesions produced with the same energy. In all lesions produced with mote than $50 \mathrm{~J}$ there was loss of mucosa, and many had loss of muscularis mucosae with deep submucosal burns (Figs. 2, 3, 4). Adjacent submucosal arteries commonly had

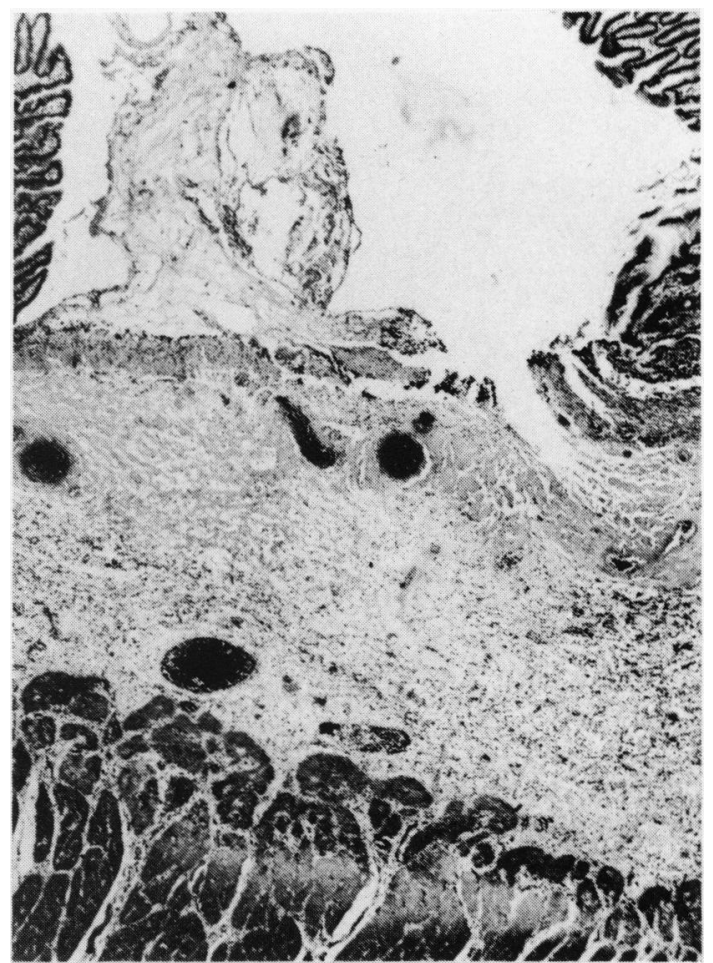

Fig. 2 Four days after laser injury to intact mucosa $(70 \mathrm{w}$, $2 \mathrm{sec}$ ). Loss of mucosa is apparent with a wide zone of submucosal connective tissue burn, and loss of muscularis mucosae ( $H \& E \times 36$ original magnification).

fibrinoid and haemorrhagic necrosis of their tunica media with organising thrombosis (Fig. 5). Around the submucosal burn and damaged vessels there was activation of fibroblasts and new capillaries. The edges of the base of the ulcer were covered by a single layer of thin, regenerating epithelium that extended over the surface of dead tissue remnants (Fig. 6). Fourteen days after laser treatment, the extent of damage was comparable with that seen after 4 days for similar energies.

Five weeks after laser treatement

No naked eye mucosal abnormality was recognised at the six sites studied. Histological examination revealed only a limited area of connective tissue burn in the submucosa and external muscle layer. The mucosa was normal.

MUCOSA IN WHICH STANDARD ULCERS HAVE BEEN CREATED USING THE 'ULCER MAKER'

No laser treatment

The histological appearance of these ulcers has been 


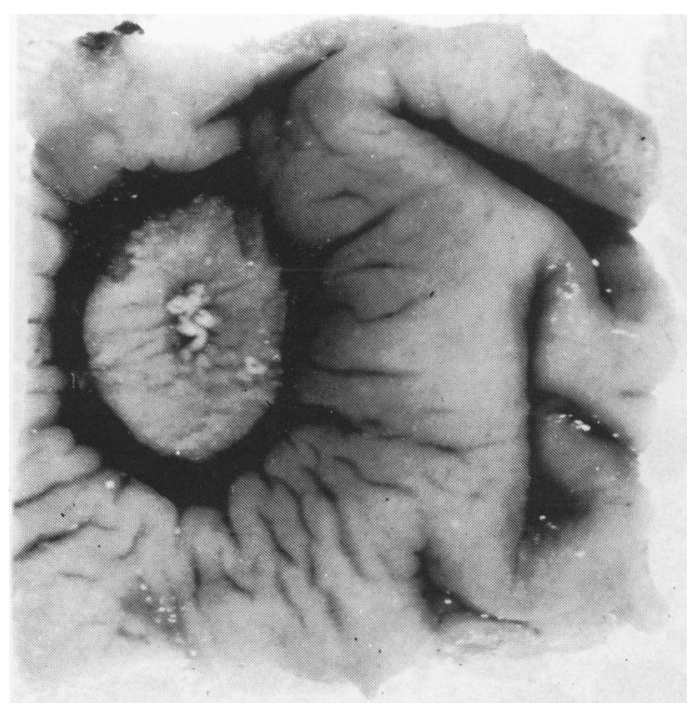

Fig. 3 Four days after laser injury to intact mucosa (70 w, $5 \mathrm{sec}$ ). Ulcer has been formed by sloughing of mucosa after treatment ( $\times 5$ original magnification).

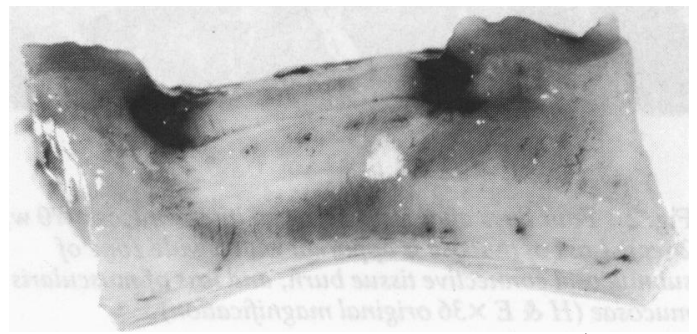

Fig. 4 Cut surface of lesion in Fig. 3 showing the elliptical zone of photocoagulation and the hyperaemic response in adjacent, non-injured tissue ( $\times 5$ original magnification).

described previously. 5 They extended to the submucosa. After seven days, there was marked inflammation and granulation tissue proliferation with partial epithelialisation of the ulcer base. Healing was essentially complete at four weeks.

\section{Effects immediately after laser treatment (complete haemostasis was achieved)}

The ulcer base was covered by blood and charred tissue and there was a wide surrounding zone of connective tissue burn affecting the submucosa and sometimes extending into the external muscle layer. There was haemorrhage, hyperaemia, and oedema of submucosal connective tissue adjacent to the ulcer. In situ mucosal damage was present lateral to the ulcer, sometimes with epithelial detachment.

One week after photocoagulation

Charred tissue was often still present over the

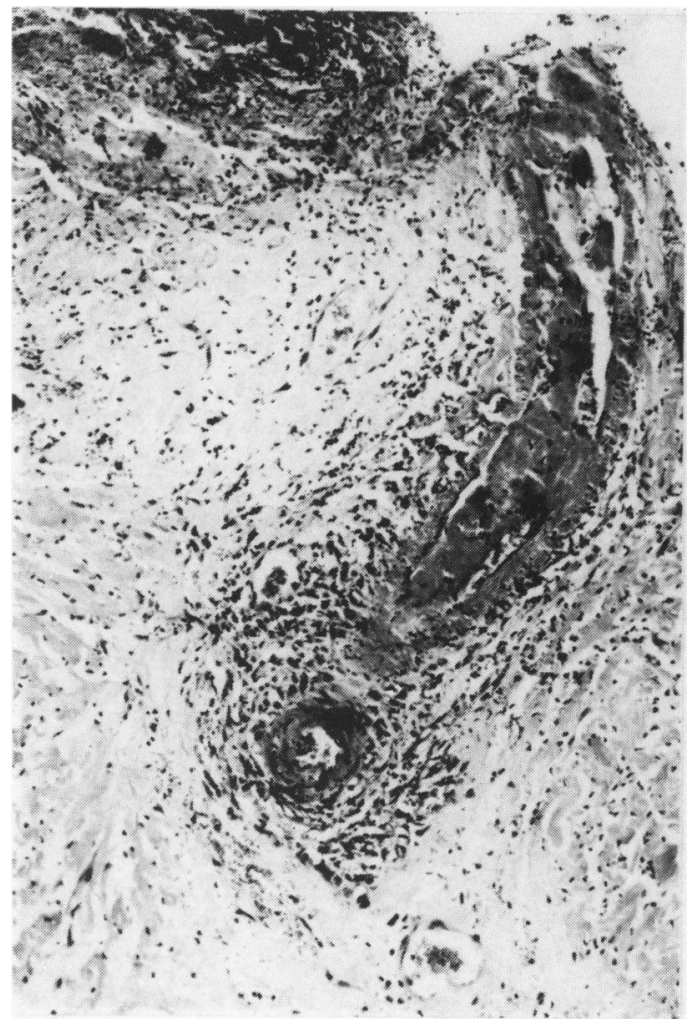

Fig. 5 Four days after laser injury. Submucosal artery with fibrinoid medial necrosis, organising thrombus and periarterial inflammation and fibrosis ( $H \& E \times 145$ original magnification).

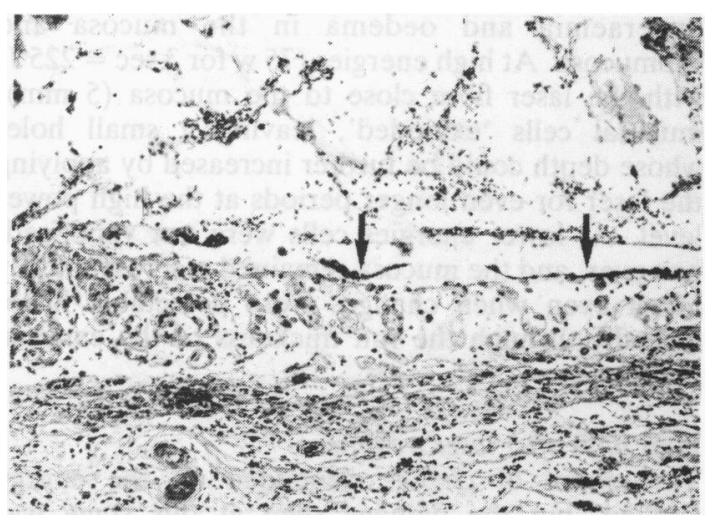

Fig. 6 Four days after laser injury to intact mucosa $(70 \mathrm{w}$, $2 \mathrm{sec}$ ). Regenerating epithelium (arrows) extends over the base of the ulcer produced by sloughing of treated mucosa ( $H \& E \times 145$ original magnification).

surface of the ulcer (Fig. 7), although in some cases the edges of the ulcer were covered by a thin layer of 


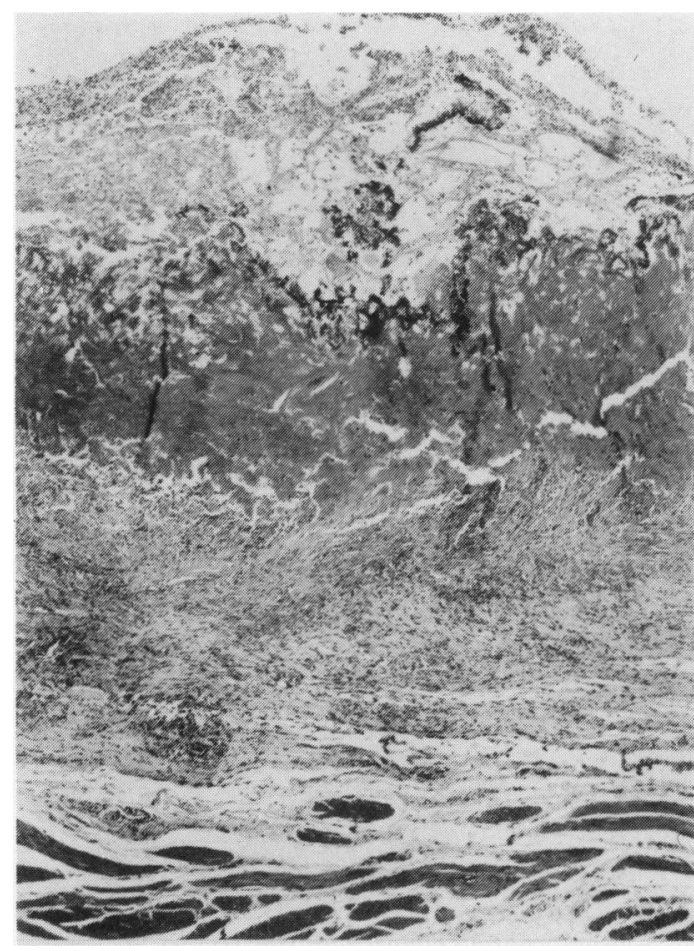

Fig. 7 Seven days after laser treatment of induced ulcer. (Total $160 \mathrm{~J})$. Inflammatory exudate and charred tissue rest on a zone of submucosal fibrous repair. External muscle layer is undamaged. ( $H \& E \times 60$ original magnification).

regenerating epithelium (Fig. 8). Arterial thrombi were being organised by endothelial cells and fibroblasts and there was extension of new capillaries and fibroblasts into the burned submucosal connective tissue.

\section{Two weeks after photocoagulation}

The ulcer illustrated in Figs. 9 and 10 (which had been treated with $300 \mathrm{~J}$ ) was still recognisable grossly and microscopically by the loss of mucosa and submucosa and the base contained cell debris. At the edges of the ulcer re-epithelialisation proceeded with atypia of adjacent mucosal glands, below which was well-formed fibrous connective tissue (Fig. 9). In some sections this extended through the full thickness of the external muscle layer (Fig. 10).

\section{Five weeks after photocoagulation}

No naked eye ulcer was recognised. Only histological remnants of the earlier processes were found: in the intact mucosa a few dilated glands contained cell debris. In the submucosa there was dense scarring in which charred tissue fragments were

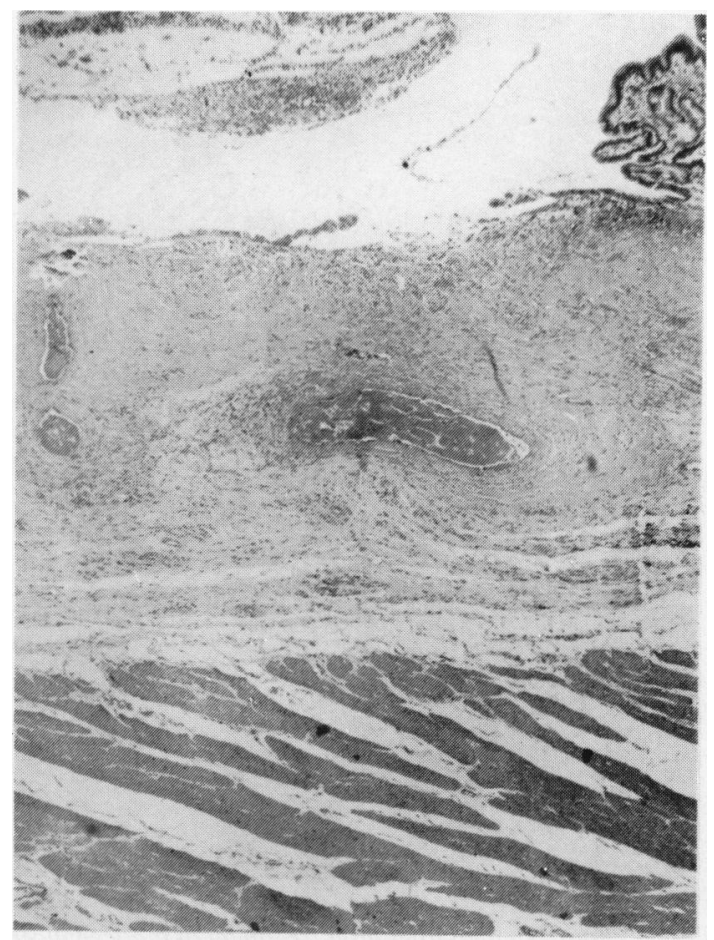

Fig. 8 Seven days after laser treatment of induced ulcer (four shots of $30 \mathrm{~J}$. Total $120 \mathrm{~J}$ ). Ulcer base with epithelial regeneration, submucosal connective tissue burn and thrombosis of damaged arteries. External muscle layer is undamaged. ( $H \& E \times 60$ original magnification).

present. There was endarterial fibrous obliteration of adjacent submucosal vessels (Fig. 11).

\section{Discussion}

The Nd YAG laser caused a wide range of effects in gastric mucosa, from mild mucosal oedema to vaporisation of cells and destruction of tissue. The effects are similar to those described after Argon laser treatment, but the extent and evolution through the healing period are quite different. The absorption coefficient for the infra-red Nd YAG beam in the stomach wall is much lower than that for the blue-green Argon beam. This has two main consequences: (a) a much higher power concentration is required (about 10 times as much) for the same amount of energy to be absorbed at the tissue surface and (b) the intensity of the beam falls less rapidly as it penetrates deeper, so similar histological changes occur through a greater depth. Argon laser lesions are only detectable for a maximum depth of $1 \mathrm{~mm}$ (and often less) below the surface (or base of the hole created by the laser), ${ }^{5}$ whereas Nd YAG lesions can involve the full 


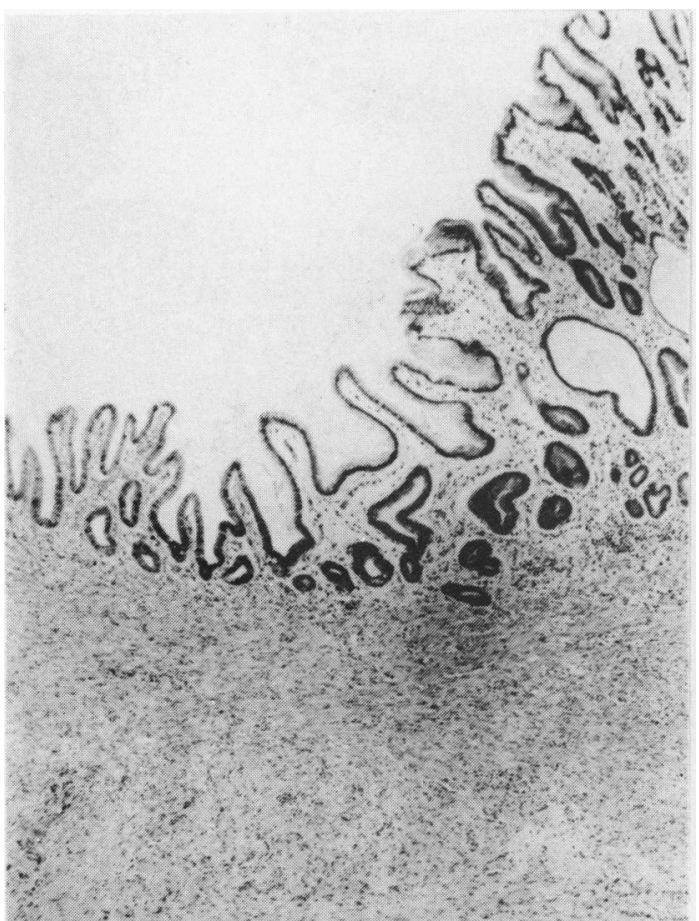

Fig. 9 Fourteen days after laser treatment of induced ulcer (5 shots of $60 \mathrm{~J}$. Total $300 \mathrm{~J})$. Epithelial regeneration covering the side of the ulcer base with underlying fibrous repair. The centre of this ulcer (not illustrated) showed persistent loss of mucosa and submucosa ( $H \& E \times 60$ original magnification).

thickness of the stomach wall before cells at the surface are destroyed. These differences influence the evolution of the histological changes through the healing period. The narrow band of partly damaged cells seen in the Argon lesions healed without further loss of tissue ${ }^{5}$ but in many Nd YAG lesions the true extent of partly damaged cells was much greater and was not visible on sections studied acutely. Mucosa which showed in situ damage initially sloughed several days later to expose the muscularis mucosae (Figs. 1-4). This delay in the appearance of the full extent of damage has been reported by others. ${ }^{24}$ Healing may also be delayed. After two weeks, Argon laser treated ulcers were not visible macroscopically, and histological examination revealed a regenerating mucosa. ${ }^{5}$ Some Nd YAG treated ulcers were still apparent macroscopically at this stage with persistent tissue loss.

Healing was, however, essentially complete after five weeks (Fig. 11). This sloughing of mucosa after four days and delayed healing may reflect partial thermal damage to the surrounding tissue, which impedes the growth of capillaries and proliferation

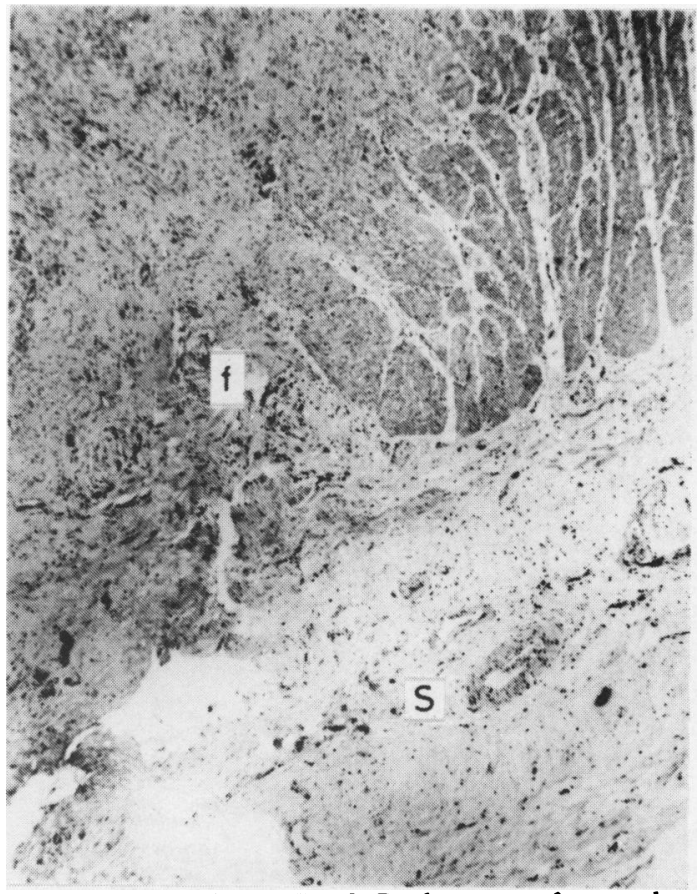

Fig. 10 Same ulcer as Fig. 9. Replacement of external muscle layer by fibrous connective tissue (f). Serosal tissue (s) is normal ( $H \& E \times 60$ original magnification).

of fibroblasts in the most severely damaged areas. If this explanation is correct, healing should be more rapid if the energy deposited in the tissue is less and our results support this. Lesions made on normal tissue with energies greater than $50 \mathrm{~J}$ showed mucosal sloughing at four days. Below $150 \mathrm{~J}$ the mucosal defect had healed by two weeks but at higher energies it had not. Also the ulcer which was still present after two weeks had been treated with five pulses of one second duration at $60 \mathrm{w}(=300 \mathrm{~J})$. We established that the optimum pulse duration was $0 \cdot 3-0 \cdot 5$ seconds with pulse energies of $25-40 \mathrm{~J}^{3}$ and Fig. 8 shows an ulcer treated optimally and examined after one week. Healing in this case is comparable with that seen one week after Argon laser treatment and in untreated control ulcers as previously described, ${ }^{5}$ suggesting that the lower energy used may have enabled healing to take place at a normal rate. This ulcer also shows considerably less damage in the external muscle layer than the one treated with $300 \mathrm{~J}$ (Fig. 10). The deep damage was often patchy, probably because of the higher proportion of the YAG beam that is scattered within the tissue, and was not seen with the Argon laser when the damage was limited to a narrow zone close to the exposed surface. In itself, patchy transmural scarring is probably not of significance as long as the 


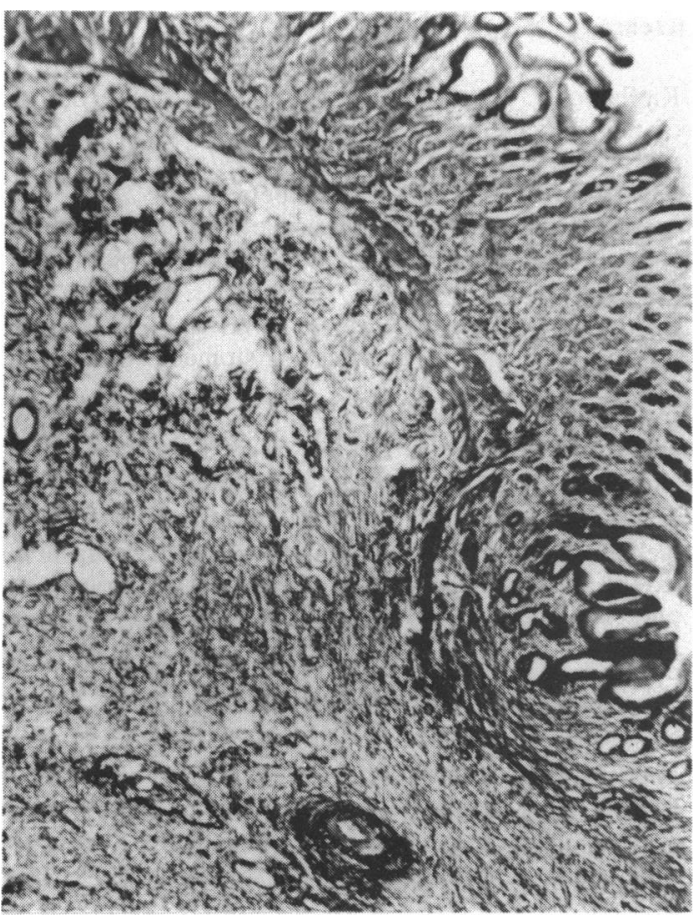

Fig. 11 Thirty five days after laser treatment of induced ulcer. The mucosa is almost completely restored above the missing muscularis mucosae. There is fibrous intimal thickening in a submucosal artery and vein. (Elastic van Gieson $\times 60$ original magnification).

mechanical integrity of the gut is maintained at all times, but this work does bring out the conditions under which deep damage can be expected. Late perforations, as reported in one clinical case, ${ }^{1}$ have not occurred in these experiments. When treating an ulcer that may already be close to perforating it is clearly important to reduce the risk of further

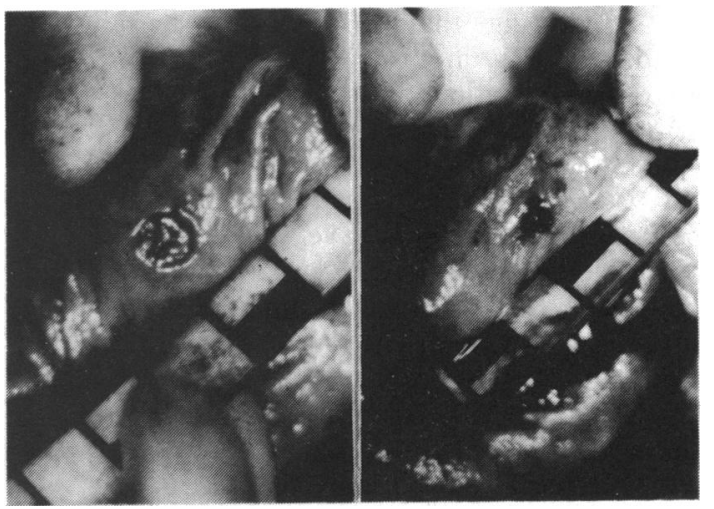

Fig. 12 Induced ulcer before (left) and immediately after laser treatment. During treatment, the ulcer contracted to one half its original size. (Marks on scale at $1 \mathrm{~cm}$ intervals.).

damage by minimising the laser energy used on any one spot, and ideally this should be kept below the energy that causes the surface layer to slough. It is possible that the serosa provides some protection against free perforation as it is transparent to the laser beam and so does not absorb much energy directly. ${ }^{\text {? }}$

Haemostasis results from thermal contraction of the walls of the bleeding vessel and of the surrounding tissue. Visible contraction of the tissue at the time of treatment was much more marked than with the Argon laser and in induced canine ulcers could be as much as $50 \%$ of the ulcer width, as shown in Fig. 12. Such dramatic contraction is unlikely in a chronic ulcer in man, in which the crater is mostly scar tissue, but the same mechanism probably applies. Denaturing of proteins in plasma may play a part, but thrombi were never seen in blood vessels immediately after treatment (even in non-heparinised animals). They were, however, often seen in lesions examined four or more days

Table Differences between effects of Argon and Nd YAG lasers

\begin{tabular}{|c|c|c|}
\hline & Argon & $N d Y A G$ \\
\hline $\begin{array}{l}\text { Depth of histological damage after treatment of standard ulcers: } \\
\text { (a) Optimum settings, } \\
\text { (b) Excessive pulse energies } \\
\text { Risk of free perforation }\end{array}$ & $\begin{array}{l}\text { Submucosa } \\
\text { Upper muscularis propria } \\
\text { Very low }\end{array}$ & $\begin{array}{l}\text { Submucosa } \\
\text { Full thickness } \\
\text { Very low }\end{array}$ \\
\hline $\begin{array}{l}\text { Healing rate: } \\
\text { (a) Optimum settings } \\
\text { (b) Excessive pulse energies }\end{array}$ & $\begin{array}{l}\text { Same as controls } \\
\text { Same as controls }\end{array}$ & $\begin{array}{l}\text { Same as controls } \\
\text { Delayed }\end{array}$ \\
\hline $\begin{array}{l}\text { Maximum extent of tissue below and on each side of laser spot that can } \\
\text { contract on treatment } \\
\text { Approximate maximum size of vessel that can be sealed } \\
\text { Minimum pulse energies at which surface cells are destroyed: }\end{array}$ & $\begin{array}{l}1 \mathrm{~mm} \\
1 \mathrm{~mm}\end{array}$ & $\begin{array}{l}5 \mathrm{~mm} \\
1.5 \mathrm{~mm}\end{array}$ \\
\hline $\begin{array}{l}\text { (a) Immediate } \\
\text { (b) Delayed } \\
\text { Optimum parameters for haemostasis }\end{array}$ & $\begin{array}{l}8 \mathrm{~J} \\
8 \mathrm{~J} \text { (delayed sloughing not seen) } \\
8 \text { watts, } 1 \text { sec } \\
(=8 \mathrm{~J} \text { pulse energy) }\end{array}$ & $\begin{array}{l}225 \mathrm{~J} \\
50 \mathrm{~J} \\
75 \text { watts, } 0 \cdot 4 \mathrm{sec} \\
(=30 \mathrm{~J} \text { pulse energy })\end{array}$ \\
\hline
\end{tabular}


later, suggesting that thrombosis occurs as a secondary phenomenon following a different primary haemostatic mechanism.

The difference between effective and dangerous treatment energies is not as great with the Nd YAG as it is with the Argon laser, but in these experimental studies we have shown that careful choice of the laser parameters can produce excellent haemostasis without causing unacceptable tissue damage or delay in healing. The differences between the two lasers are summarised in the Table. A controlled clinical trial is now in progress for the endoscopic treatment of haemorrhage from peptic ulcers with the Nd YAG laser.

We should like to thank Professor G H Arthur and the staff of the Department of Veterinary Surgery, University of Bristol for their help and advice throughout this project; Mrs M Maddocks for the histological preparations, Mr C C Jeal and Paula Jenkins for the photography and Miss Julie Forster for typing the manuscript. We should also like to thank Brocades (Great Britain) Ltd and MBB Ltd for loaning the Medilas laser with which these experiments were performed. This work was carried out with the support of a grant from the DHSS.

\section{References}

1 Kiefhaber P, Nath G, Moritz K. Endoscopical control of massive haemorrhage by irradiation with a highpower Nd YAG laser. Prog Surg 1977; 15: 140-55.

2 Silverstein FE, Protell RL, Gilbert DA et al. Argon versus Neodymium YAG laser photocoagulation of experimental canine gastric ulcers. Gastroenterology 1979; 77: 491-6.

3 Bown SG, Salmon PR, Storey DW, et al. Nd YAG laser photocoagulation in the dog stomach. Gut 1980; 21: $818-25$.

4 Rutgeerts P, Vantrappen G, Geboes K, Broeckaert L. Safety and efficacy of Neodymium YAG laser photocoagulation: an experimental study in dogs. Gut 1981; 22: 38-44.

5 Kelly DF, Bown SG, Salmon PR, et al. Nature and extent of histological changes induced by Argon laser photocoagulation in canine gastric mucosa. Gut 1980; 21: $1047-55$.

6 Protell RL, Silverstein FE, Piercey J, Dennis M, Sprake W, Rubin CE. A reproducible animal model of acute bleeding ulcer - the 'ulcer maker'. Gastroenterology 1976; 71: 961-4.

7 Dixon JA, Berensen MM, McCloskey DW. Neodymium YAG laser treatment of experimental canine gastric bleeding. Gastroenterology 1979; 77: $647-51$. 